\title{
Para uma antropologia histórica dos povos indígenas: reflexões críticas e perspectivas
}

\section{For a historical anthropology of indigenous peoples: critical reflections and perspectives}

João Pacheco de Oliveira*

* Museu Nacional/Universidade Federal do Rio de Janeiro - Rio de Janeiro, RJ, Brasil jpo.antropologia@mn.ufrj.br

https://orcid.org/0000-0003-2485-2147

Pablo Quintero**

**Universidade Federal do Rio Grande do Sul - Porto Alegre, RS, Brasil pablo.quintero@ufrgs.br https://orcid.org/0000-0003-4111-9895 


\section{Introdução}

Este número reúne trabalhos de pesquisa que se situam no cruzamento entre, de um lado, uma modalidade de fazer antropológico aqui referida sinteticamente como antropologia histórica, e, de outro lado, os povos indígenas, pensados como sujeitos políticos portadores de direitos e de protagonismo.

Antropologia e história constituem exercícios voltados para uma profunda compreensão do Outro, ou seja, de uma forma de existência social bem distinta daquela do narrador e de seu público, seja em termos geográficos ou cronológicos. Uma separação entre elas, remetendo a domínios e métodos distintos, não pode ser encontrada nas obras de muitos dos seus mais clássicos fundadores, como Lewis Morgan, Max Weber, Franz Boas, Marc Bloch ou Fernand Braudel. Essa ruptura veio a ocorrer somente em um momento seguinte, quando esses conhecimentos ingressaram nos espaços universitários e precisaram cristalizar-se em disciplinas distintas (Lander, 2000).

Para uma história da ciência positivista se trataria apenas de movimentos de diferenciação e especialização próprios a todo processo de "evolução social". Mas para uma perspectiva crítica é preciso destacar que essa incorporação às universidades se deu sob a hegemonia das ciências naturais e segundo os pressupostos epistemológicos que as instituíram. Nesse sentido as preocupações caminham sobretudo para a definição de métodos que fossem compatíveis com as ciências mais reconhecidas. Isso ocorre também em paralelo ao aperfeiçoamento de dispositivos de controle e vigilância na sociedade capitalista durante um acelerado processo de expansão colonial e de disputa de mercados. É em decorrência desse cenário que, como nos lembra Talal Asad (1973), as ciências sociais se desenvolveram como disciplinas universitárias fabricando as suas identidades de maneira fragmentária e contrastiva.

Com Malinowski (1978) táticas e estratégias de investigação tornaram-se emblemas identitários. O trabalho de campo, o corte sincrônico e o uso da língua nativa passaram a ser tidos como a marca da pesquisa antropológica. A fonte de informação confiável tornou-se apenas o registro direto feito por um observador treinado: o etnógrafo, que assegurava assim para si o monopólio do saber científico sobre as sociedades primitivas (Tuhiwai Smith, 1999). Em paralelo se distanciava radicalmente dos historiadores ao minimizar a importância dos arquivos e das reconstruções do passado. 
Ao abordar as sociedades não ocidentais através de um olhar puramente relativista e exotizante, recusando-se a considerar a dominação colonial como um fator heurístico crucial, a antropologia funcionalista abriu caminho para um gênero narrativo que inseria as populações pesquisadas em um universo ficcional do qual estavam ausentes os conflitos, as variações e o porvir histórico. Como dizia Leach (1972), de modo lapidar, algumas décadas depois, a antropologia (tomando o funcionalismo como definidor da disciplina) apresentava os seus objetos, as sociedades primitivas, como se vivessem em um permanente presente, sendo assim "hoje e para sempre" (now and forever).

Uma outra forma de construir uma dissociação entre antropologia e história veio do estruturalismo francês. $O$ foco de interesse da antropologia não seriam as ações em si mesmas nem as motivações que as engendrariam temas estes para o historiador - mas as estruturas e modelos inconscientes descobertos pelo pesquisador. O antropólogo estrutural, como um "astrônomo das ciências sociais", teria a sua análise fundada num distanciamento radical entre sujeito e objeto de conhecimento (Lévi-Strauss, 1967, p. 422).

Em decorrência desses pressupostos a antropologia estrutural estabeleceu como exterior ao seu campo de investigação a dimensão do poder nas ações humanas. Estas eram compreendidas sempre através de estruturas inconscientes e atemporais que anulavam o protagonismo de atores e coletividades. Paralelamente supunha-se que o pesquisador, ao ingressar em outras locações espaciais, poderia, através da mágica passagem pelo trabalho de campo intensivo e localizado, tornar-se desenraizado da perspectiva ocidental e da herança colonial. O investigador, assim, autorrepresenta-se como um sujeito de conhecimento universal, a qualidade de sua imersão no mundo nativo sendo assegurada por meio da exibição de um grande domínio linguístico e etnográfico. Ao mesmo tempo que referências afetivas e frases de impacto usadas de forma literária pretendem atestar a empatia desse encontro entre pesquisado/a e pesquisador/a e legitimar moralmente e esteticamente o experimento.

A recomendação feita por Malinowski (1978) quanto a afastar-se dos agentes coloniais típicos, como missionários e administradores, cujas representações e práticas em relação aos nativos poderiam comprometer a originalidade da investigação, resultava de uma crença ingênua e equivocada sobre um possível apagamento da condição colonial na produção dos próprios dados 
e interpretações. Mas isso se transforma em um ponto cego das investigações antropológicas posteriores, inclusive em outras vertentes teóricas. Um dos primeiros autores a falar em uma antropologia histórica, Bernard Cohn, um estudioso da Índia, já apontava como tais pressupostos eram insustentáveis, seja para a pesquisa etnográfica ou aquela feitas em arquivos: "Nor does the scholar begin as a tabula rasa to be instructed by the native or the document, nor is he or she merely a pencil which records in some fashion what is read or seen" (Cohn, 1992, p. 220). Abandonando uma posição meramente normativa é importante realizar uma descrição e análise das condições em que foram produzidos os dados e as interpretações, referindo-os a um conjunto concreto de inter-relações sociais (expectativas, obrigações e conflitos) engendradas entre o/a pesquisador/a e os pesquisados/as. ${ }^{1}$

Numa perspectiva crítica é fundamental ter presente que as sociedades não ocidentais foram sempre objeto de observação e estudo dentro de situações coloniais, fato cujas profundas consequências não se constituíram em tema de reflexão para a antropologia funcionalista nem para a antropologia estrutural (Rodríguez, 1991).

Uma tal omissão, frequentemente ancorada etnograficamente nos relatos dos mais velhos e na rememoração de tradições unicamente supostas como autóctones, colocava tais sociedades como se estivessem em uma forma de existência fora do tempo e da história (Fabian, 2013). Tais modelos de investigação terminam por repetir (sem se dar conta) as antigas práticas de produção de conhecimento realizadas na formação de coleções para os museus de antropologia. As monografias e as interpretações apresentadas seguem decantadas das marcas de violência que presidem a sua atualização, assim como da eficácia social, afetiva e histórica:

Nesse movimento, mesmo depois de sair dos museus e tomar como cenário as salas e os anfiteatros das universidades, os antropólogos não mudaram profundamente as suas práticas de investigação, continuando a coisificar os seus

1 A noção de "situação etnográfica" (Pacheco de Oliveira, 1999, p. 9-10) pretende justamente estimular a investigação desses quadros interativos (sempre considerados em sua multiplicidade) em que ocorrem as pesquisas, propondo assim transformar tais interconexões em um objeto de estudo e etnografia. 
"outros", redispondo-os segundo séries históricas e analíticas construídas a partir de referenciais externos. As galerias foram substituídas por teses, livros, artigos, power-points e vídeos, nos quais se anunciava ao público o índio destilado de iniciativas próprias ou de espessura e resistência, um ator cultural retirado de seu contexto social. Uma experiência humana devassada (em termos de etnografia) e lógica (em termos de sistemas), despojada de periculosidade e protagonismo. (Pacheco de Oliveira; Santos, 2019, p. 10).

\section{A diversidade do fazer antropológico}

As recomendações de Malinowski e Lévi-Strauss quanto ao afastamento entre antropologia e história acima colocadas não dão conta da riqueza e complexidade daquilo que as/os antropólogas/os efetivamente fazem e fizeram. Constituem modos de objetificação que, no interior de uma disciplina em formação, ajudaram-na a consolidar-se e serviram como inspiração para muitas pesquisas e trabalhos importantes. Mas se forem tomadas como um método universal de produção de conhecimentos, à semelhança das ciências naturais ou da linguística, implicam circunscrever o horizonte da disciplina, simplificam e empobrecem o legado de suas contribuições, colidem com as múltiplas condições e objetivos do exercício concreto, e crítico, da antropologia.

Uma parte muito importante dos contemporâneos daqueles autores não colocou em prática tais protocolos de conhecimento e até mesmo manifestou o seu desconforto com eles. Na antropologia inglesa a rejeição de Malinowski à história é diretamente questionada por Max Gluckman (1963) e Evans-Prittchard (1962) e não é de forma alguma seguida pelo conjunto de africanistas (como J. A. Barnes, 1954 e Victor Turner, 1957). Nas décadas seguintes se expressa na contundente crítica de Edmund Leach (1972) ao funcionalismo, nas etnografias históricas sobre o passado europeu (Goody, 1983; Keith, 1971), bem como em outras obras de Maurice Bloch (1975) e Jack Goody (2012), que dialogam extensamente com a história. Também se reflete nos estudos americanistas atuais com John Gledhill (1985, 2000) e Mark Harris (2010).

$\mathrm{Na}$ antropologia francesa igualmente os trabalhos de figuras exponenciais como Marcel Mauss (2003) e Maurice Halbwachs (1950) remetem a outras direções. A depender da região etnográfica, despontam obras que 
formulam orientações bem diversas, como a de Marcel Granet (1968) sobre a China, Michel Griaule (1938) sobre os Dogon da África ocidental e até mesmo de Louis Dumont (1966), investigando sobre o sistema de castas na Índia. Para as ilhas do Pacífico também o exercício da antropologia segue um rumo totalmente diferente, primeiro com os trabalhos de Maurice Leenhardt (1947) e mais tarde com a etnografia e as reflexões de Alban Bensa (1995). Os estudos africanistas, em que Georges Balandier (1955) ocupou um papel de destaque, avançaram igualmente com pressupostos analíticos muito distintos do estruturalismo, o que se expressou na obra de Jean-Loup Amselle e Elikia M'Bokolo (2017), Jean Bazin (2014), Marc Augé (1975) e Michel Agier (2010). Os estudos americanistas, reduto do estruturalismo na antropologia francesa, foram duramente criticados pelos africanistas em uma importante coletânea intitulada Le sauvage à la mode (Amselle, 1979), e também os oceanistas operam com pressupostos inteiramente divergentes da antropologia estrutural (Bensa, 2016).

Nos Estados Unidos, através do evolucionismo cultural de Lewis Morgan e do culturalismo de Alfred Kroeber, a antropologia inicialmente manteve-se próxima da arqueologia, depois se voltando para uma forte conexão com a história, como sucedeu com Eric Wolf (2009), Marshall Sahlins (1990), William Roseberry (1989), Sidney Mintz (1996), Gerald Sider (1988), Michael Taussig (1993), Joanne Rappaport (1994), June Nash (1993, 2008), James Clifford e George Marcus (1991) e com os sul-africanos Jean e John Comaroff (1992). Cabe lembrar também as fortes críticas formuladas por autores que expressavam correntes centrais na antropologia americana como Marvin Harris (1979) e Clifford Geertz (1987).

Um destaque especial deve ser feito para o monumental trabalho de Eric Wolf (2009) resgatando parcialmente a história dos povos não ocidentais e apontando a centralidade destes na formação do mundo europeu, trabalho que convida a romper com a atomização dos estudos antropológicos, a reificação de processos históricos e a essencialização de categorias analíticas e sujeitos sociais. Isso nos exige também repensar os limites entre antropologia e história.

Na América Latina há fecundas tradições no estudo da antropologia e dos povos indígenas. No Brasil deveríamos lembrar de obras como as Darcy Ribeiro (1970) e Roberto Cardoso de Oliveira (1978). No México foi cunhada uma rica tradição de estudos que associou antropologia e história, com Angel Palerm (1980), 
Arturo Warman (1970), Rodolfo Stavenhagen (1969), Guillermo Bonfil Batalla (1992), entre outros. Isso para limitar-nos apenas a esses dois países, sem falar do argentino Eduardo Menéndez (1971), do cubano Fernando Ortiz (1978), do haitiano Jean Casimir (1980), do peruano José María Arguedas (1975) e da venezuelana Iraida Vargas (1980). Quando as/os antropólogas/os latino-americanas/os postulam objetos e práticas distintas de trabalho científico não estão seguindo modismos das antropologias ditas centrais (mainstream), mas retomando posicionamentos críticos e inovadores que deixaram raízes profundas em seus países.

\section{A antropologia atual e seus muitos "outros"}

Há que considerar, por outro lado, que novos "objetos" de estudo vieram a se impor à antropologia, que foi progressivamente deixando de ser o estudo das sociedades chamadas "primitivas", como era muitas vezes descrita até as primeiras décadas da segunda metade do século XX (Copans, 1988). Muitos novos objetos surgiram como os seus "outros" e passaram a demandar igual atenção das/os praticantes da disciplina: comunidades camponesas, inclusive indígenas e descendentes da diáspora africana; instituições e rituais em sociedades ditas "complexas"; uma antropologia das cidades e de nações; minorias nacionais, grupos étnicos e setores sociais marginalizados e estigmatizados; estudos de gênero; museus, memória e colecionismo; imagens, artes e patrimônio cultural; o estudo das emoções e formação de subjetividades; e domínios novos, como as mídias e tecnologias de comunicação (Peterson, 2003), e agência de outros seres vivos (Ingold, 1987). Inclusive com desdobramentos muito importantes e inspirados na história sobre as condições sociais da etnografia, a formação de escolas de pensamento, as antropologias nacionais e a multiplicidade em escala mundial de fazeres antropológicos, como os trabalhos de George Stocking (1982), Johannes Fabian (2013), Mary Louise Pratt (1997) e Ribeiro e Escobar (2012).

Igualmente a história ampliou muito os seus objetos de investigação, afastando-se do estudo da história moderna da Europa e das novas nações, em que o pesquisador mantinha conexões e afinidades com os assuntos abordados. Nesse movimento, os historiadores vieram a mergulhar em temas considerados 
menores para a consciência iluminista, como o mundo medieval, as heresias religiosas e a bruxaria (Bloch, 1996; Murray, 1971). Ou abordaram temas encobertos e ameaçadores para a sua própria inserção social, como o estudo da classe operária, de camponeses e revoltas sociais (Darnton, 1995; Thompson, 1995), ou ainda das instituições disciplinadoras dos corpos e das mentes (Foucault, 1985). Ou, inversamente, tratando de assuntos considerados demasiado ambiciosos ou próximos, como as interconexões globais ou a história do tempo presente (Wallerstein, 1974), ou ainda focalizando temas pouco valorizados como o estudo da vida cotidiana, da política local e da cultura popular (Ginzburg, 1987). Em tais investigações não seria possível supor que o historiador não praticasse o distanciamento social e buscasse os instrumentos para a sua superação.

A repercussão dessas transformações nos "objetos", temas e práticas da antropologia ainda está por ser mais bem explorada e analisada. Longe de ser uma construção arquitetônica coesa e integrada, a antropologia possui domínios bastante diferenciados, assim como saberes regionalizados (Fahim, 1982), dentro dos quais, efetivamente, processa-se a transmissão e a avaliação de práticas específicas de pesquisa, algumas vezes com fortes aproximações a autores e procedimentos de outras disciplinas. Nem sempre "os protocolos de pesquisa que operam nesses domínios estão em perfeita sintonia com aqueles que ocupam um lugar privilegiado na disciplina como um todo" (Pacheco de Oliveira, 2013, p. 69).

\section{Um horizonte em construção}

Atualmente, há um distanciamento muito grande entre as práticas concretas de investigação e o discurso normativo, que dirige o ensino e a formação de novas/os antropólogas/os e engendra hierarquias e exclusões. Como foi dito anteriormente, os protocolos de pesquisa que geraram as "condições de possibilidade da prática antropológica, formatando gostos e valores e permitindo aos antropólogos a cristalização de uma identidade própria, não fornecem mais uma carta de navegação satisfatória e confiável" (Pacheco de Oliveira, 2013, p. 49). Ao contrário, instauram uma pressão homogeneizadora, ancorada em uma normatividade repressora referida a momentos passados da disciplina 
que tendem a configurar padrões de reprodução profissional acrítica e politizada só nas aparências (Díaz-Polanco, 2008; Quintero, 2015).

Não é mais possível que pesquisas contemporâneas continuem sistematicamente a tratar os povos indígenas como sociedades estáticas, cujos únicos instrumentos para a compreensão e revalorização são a exotização das diferenças (Bensa, 2015), a relativização das culturas e a negação da coetaneidade entre pesquisador e pesquisado (Fabian, 2013). A partir de uma perspectiva fenomenológica que apaga relações histórico-sociais fundamentais (Marx, 2007), as sociedades indígenas são imaginadas como um santuário absoluto de diferença e da externalidade cultural, sendo apresentadas como a exemplificação perfeita de modos de vida e de pensamento que supostamente não afetam, nem são afetados, pelas dinâmicas gerais do mundo moderno, do capitalismo e da colonialidade (Coronil, 1999; Quintero, 2012). A poética e a política dessas representações está comprometida com a anulação do protagonismo indígena e o rechaço de uma consciência crítica quanto às condições atuais de exercício da pesquisa antropológica.

Essas práticas que modelaram os objetos clássicos da antropologia decorrem do que o antropólogo haitiano Michel-Rolph Trouillot (1991) chamou de "lugar do selvagem" (savage slot): uma criação do Renascimento europeu baseada na configuração de estados ideais de humanidade caracterizados por "ausências constituintes" do Ocidente. Essa forma de construção dos outros tem como elementos centrais a ambiguidade e ambivalência do exótico e do pristino, possuindo como tendências, ao mesmo tempo, a celebração e o rechaço dessa outridade. Um tal discurso que se assenta durante a colonização da América e a consolidação do capitalismo na Europa acompanha os exercícios identitários da própria modernidade (Dussel, 1994).

Essa perspectiva disciplinar tendeu a configurar um modelo antitético fundamentado em binarismos que classificavam as sociedades em modernas/tradicionais, complexas/simples, capitalistas/pré-capitalistas, com Estado/sem Estado, de pensamento racional/pensamento mítico, com história/sem história, simulando apenas descrever enquanto, de fato, estabeleciam uma diferença essencialmente hierárquica entre povos, culturas e sociedades. Longe de contribuir com a defesa da diversidade histórico-cultural, tais pares de correlatos têm sistematicamente servido como fonte de motivação e inspiração de fantasias coloniais (Abu-Lughod, 1991; Said, 2003) que reproduzem o exotismo do lugar do selvagem. 
Nesse contexto falar de antropologia histórica não poderia de forma alguma significar uma junção acrítica de métodos e teorias que circulam nessas duas disciplinas. Assim como a antropologia configurou seus outros desde uma visão parcial e a partir de interesses específicos, a história também privilegiou personagens e agências, construindo silêncios significativos no próprio processo de construção do histórico (Said, 1996). De nada serve à antropologia se conectar à história - e vice-versa - se não forem revisitados os fundamentos de tais disciplinas e, sobretudo, deslocadas criticamente as suas autorrepresentações (Coronil, 2011). Isso exige um movimento metodológico e teórico de trabalhar a partir das disciplinas em sua riqueza e complexidade, em disseminar a dúvida sobre qualquer tipo de modelo essencialista, sem ter que se restringir a formas de controle de discurso e a normatividades eventuais e passageiras.

Pensar as tradições etnográficas como o resultado de uma autoconsciência progressiva quanto à eficácia e singularidade de práticas setoriais de pesquisa, ancorando-as em contextos históricos precisos, mas buscando estabelecer paralelamente suas potencialidades e limitações, pode representar uma forma positiva e criadora de escapar ao dilema de uma antropologia universal. Uma perspectiva hermenêutica, pluralista e libertária, deve acompanhar esse movimento.

Ao falar em antropologia histórica, estamos apenas sinalizando um amplo esforço de superação, que se baseia no exame concreto das práticas de pesquisa, nos seus produtos e implicações. Nesse movimento impõem-se duas marcas cruciais - chamar a atenção, primeiro, para a importância do poder na constituição dos fatos e dinâmicas sociais e, segundo, para a inter-relação (dialógica e dialética) entre pesquisador/a e pesquisado/as no processo de conhecimento.

Nesse sentido, a antropologia histórica, tal como pensada por diversas/os autoras/es, ${ }^{2}$ configura-se como um campo de estudos aberto a novos temas, métodos de investigação e protocolos de conhecimento. No caso específico dos povos indígenas, tal abordagem pretende contribuir para a visibilização e o protagonismo desses povos como atores políticos e sociais dentro de situações históricas específicas, em um movimento analítico no qual a consideração da cultura

2 "No quick packaging of the skills, methods, insights and findings in handbooks can substitute for the act of doing an anthropological history" (Cohn, 1992, p. 221). 
não implica o abandono da historicidade nem a omissão da reflexividade. Esse modo de pesquisa sobre - e com! - os povos indígenas acarreta o duplo movimento epistemológico de considerar o passado como um problema etnográfico ao mesmo tempo que analisa o presente como um problema histórico (Comaroff; Comaroff, 1992).

\section{Os povos indígenas como protagonistas}

Ao falarmos em povos indígenas não estamos procedendo a uma objetificação redutora, como ocorre nas práticas administrativas das agências governamentais, que apenas consideram como efetivamente "indios" aqueles que habitam no interior de terras indígenas reconhecidas pelo Estado, estando de algum modo sujeitos ao regime tutelar (ainda que a assistência fornecida lhes seja precária ou omissa). Não operamos igualmente com a arbitrária etnificação implícita em algumas abordagens acadêmicas, que circunscrevem o seu foco analítico a sociedades que mantenham exclusivamente línguas "próprias" e que se configurem como mônadas culturais, as bolas de bilhar na metáfora irônica que Eric Wolf (2009) toma emprestada de Norbert Elias (1987), que possam ser descritas em termos endógenos e radicalmente contrastantes com a chamada "sociedade nacional" e, por extensão, o Ocidente (Quijano, 2006).

As formas de classificação impostas por impérios ou por Estados nacionais, assim como as objetificações produzidas por métodos, teorias e escolas antropológicas, não foram de modo algum acriticamente assumidas e internalizadas por nenhum/a dos/as autores/as deste número. O primeiro estudo de caso, por exemplo, trata de um povo indígena, os Tapeba, cujo etnônimo - tal como dezenas de outros habitando o nordeste, o leste ou mesmo a Amazônia - não aparece nas listas elaboradas pela administração colonial portuguesa, nem pela agência indigenista republicana, o Serviço de Proteção aos Índios (SPI). Tão pouco é mencionado na descrição das áreas culturais indígenas (Galvão, 1979) - assim como em outros balanços da produção etnológica brasileira - que, reforçando o senso comum, muitas vezes limita-se à Amazônia, como realizado por Viveiros de Castro (1996).

Neste volume poderão ser encontrados igualmente estudos que, afastando-se das expectativas convencionais quanto ao trabalho de campo em 
regiões supostamente isoladas do Amazonas, estabelecem ou aprofundam novos eixos temáticos, como modos de dominação e exploração, formas de territorialização, estudos em arquivos, relações de gênero, regimes de memória, temporalidades diversas. O número finaliza com um estudo sobre as mobilizações políticas recentes dos Wapichana (RR), tema relativamente raro na etnologia indígena, realizado justamente por um antropólogo indígena. Isso aponta de modo bastante emblemático e feliz para a crescente produção de trabalhos elaborados por jovens pesquisadores, intelectuais e ativistas indígenas que ingressaram na carreira de antropólogo e trazem novos horizontes e desafios para essa disciplina.

\section{Sobre os artigos deste número}

Dessa maneira, este número de Horizontes Antropológicos contempla um conjunto de artigos que, abarcando uma grande diversidade de temáticas e enfoques, demonstra a variedade e a amplitude das pesquisas feitas a partir da antropologia histórica. Em particular, tais trabalhos interessam-se por reconstruir trajetórias e processos dos povos indígenas, resgatando os diferentes e complexos contextos situacionais que abrangem essas populações dentro de marcos espaçotemporais mais amplos. Longe de considerar as sociedades indígenas como sujeitos sociais passivos, os artigos deste número retratam múltiplas modalidades de agencialidades indígenas, inclusive dentro de conjunturas estruturais sumamente adversas, demarcadas por múltiplas situações coloniais. Para além dos aportes individuais que cada artigo traz ao número temático, a contribuição de todos, no seu conjunto, consiste em trazer um olhar qualificado para processos, atores, relações e acontecimentos esquecidos e apagados pelas histórias e antropologias "estabelecidas" (Stoler, 2010) ou "à la mode" (Bensa, 2016). Nesse sentido, tais artigos afastam-se das representações próprias do "lugar do selvagem" e se transformam em ferramentas de trabalho colaborativas com e dos povos indígenas.

Cada um dos artigos, incluindo os mais biográficos e centrados em personagens específicos (p. ex. Barretto Filho; Flores), abre uma paisagem sociocultural que demonstra um universo maior de relações que não se limita aos sujeitos específicos retratados nos seus textos. Ao contrário disso, seus exercícios 
analíticos são o reflexo de um universo de processos e dinâmicas nas quais as etnobiografias formam parte de uma totalidade histórica. Analogamente, os artigos que relatam processos espaçotemporais mais longos (p. ex. Mongua Calderón e Langdon; Mura, Silva e Almeida), ou agentes sócio-históricos que não se restringem a uma comunidade, localidade ou etnicidade (como Rossi Idárraga e Aleixo Wapichana, que trabalham a partir de movimentos e organizações), não esquecem a presença reiterada de sujeitos históricos alocados em contextos socioculturais específicos. Respondem, ao mesmo tempo, a dinâmicas intersubjetivas com repertórios, recursos e estratégias próprias que podem fazer parte de tradições independentes, ou, como se demonstra em outros trabalhos do número, são respostas limitadas desenvolvidas em contextos de férrea violência, exploração e subordinação (p. ex. Arruda; Menezes; Quintero e Maréchal). Nessa linha, concepções e perspectivas êmicas que se referem a territorialidades e temporalidades específicas aparecem em alguns dos artigos do número (p. ex. Amorim; Bianchi) enquanto formações subjetivas que retratam tanto modos de percepção e organização do modo de vida quanto processos políticos contemporâneos que (re)configuram ou (re)ativam essas formações dentro de intrincados cenários interétnicos.

Os artigos também exploram distintas regiões e estados no Brasil, bem como, em menor medida, da Colômbia e do Equador, trabalhando, assim, com uma significativa diversidade de populações indígenas: bakairi (MT), baniwa (AM), baré (AM), kaingang (RS), kaiowa (MS), kulina (AM), macuxi (RR), ñandéva (MS), tapeba (CE), tucano (AM), wapichana (RR), e do Xingu (MT), misak (Departamento do Cauca, Colômbia) e siona (Departamento do Putumayo, Colômbia e Província do Sucumbios, Equador). Apesar dessa amplitude, um fio condutor comum perpassa os distintos exercícios de antropologia histórica aqui desenvolvidos, a saber, as insistentes práticas de subalternização das quais historicamente as populações indígenas têm sido alvo - o que coloca em primeiro plano a sua continuada e persistente luta pela vida e pelos seus direitos territoriais, culturais e políticos.

O número temático inicia-se com o artigo de Henyo Trindade Barretto Filho "Zé Zabel Perna-de-Pau: perspectiva histórico-antropológica sobre uma tradição oral tapeba", que, dentro dos esforços de articulação das memórias históricas dos Tapeba, reconstrói as trajetórias históricas e políticas de uma importante liderança, José "da Isabel" Alves do Reis, mais conhecido como Zé Zabel Perna-de-Pau. A partir de fontes primárias, registradas ao longo de 
muitos anos de trabalho com os Tapeba, e da reconstrução de fontes secundárias, Barretto Filho realiza um trabalho etnobiográfico através das vozes polifônicas da tradição oral desse povo indígena do Nordeste. O texto coteja e sistematiza múltiplas narrativas sobre o Zé Zabel Perna-de-Pau com o objetivo de construir uma metanarrativa aberta à compreensão de fenômenos socioculturais, políticos e históricos mais amplos. Além disso, também brinda a possibilidade de conhecer e se aprofundar nos modos de vida tapeba e nas suas principais dinâmicas territoriais durante a primeira metade do século XX.

Centrado também na reconstrução biográfica de um personagem "singular", o trabalho de José Manuel Flores "Um andarilho pelo sertão do Brasil: mimese, ambivalência e agência indígena no sul de Mato Grosso", representa um interessante exercício de antropologia histórica. Valendo-se das categorias conceituais de mimese e, em menor medida, de ambivalência e agência/agencialidade, reconstrói a história de Uribatan da Silva Rondon, homem que entre 1955 e 1962 percorreu as aldeias e postos indígenas do estado de Mato Grosso (atualmente Mato Grosso do Sul) apresentando-se como capitão e fiscal geral dos índios no Brasil, além de se autodescrever como indígena e filho de ninguém menos que o Marechal Cândido Mariano da Silva Rondon, fundador do Serviço de Proteção aos Índios (SPI). Através de fontes secundárias e depoimentos de diversos funcionários públicos e de indígenas aldeados, o autor evidencia, através da figura de Ubiratan, a encarnação e reprodução do regime tutelar. Não só pela disposição do próprio personagem em defender a sua autoridade como capitão e fiscal de índios, senão pela ação das pessoas que, na época, acreditaram na sua autoridade, dirigindo-lhe queixas e demandas com base na sua condição de representante estatal.

O Serviço de Proteção aos Índios, referência indispensável para reconstruir a história indígena no Brasil durante o século XX, é, também, objeto do artigo de Lucybeth Camargo de Arruda, intitulado "Doando brindes e construindo relações através de imagens e documentos do Serviço de Proteção aos Índios (SPI)". Dessa vez, o exame sobre o SPI remete, cronologicamente, ao início da década de 1940 e está centrado analiticamente na atuação do órgão entre os povos do Xingu e bakairi no Posto de Atração Simões Lopes. Baseando-se na exploração de fontes secundárias, bem como em importantes referenciais teóricos (como Marcel Mauss e Henri Lefebvre) e tendo como chave analítica a "doação de brindes" enquanto estratégia do órgão indigenista, a autora desenvolve uma 
explicação densa sobre as implicações desse fenômeno tanto nas dinâmicas de "contato" interétnico - nos "pontos de sutura" - quanto dentro dos espaços propriamente indígenas. Se os brindes de objetos podiam ser vantajosos para os funcionários do SPI, eles também foram apropriados e ressignificados pelos indígenas do Xingu e bakairi, enquanto mostra de complexas e dinâmicas agencialidades indígenas.

Na sequência, o artigo conjunto de Pablo Quintero e Clémentine Maréchal "Populações kaingang, processos de territorialização e capitalismo colonial/ moderno no Alto Uruguai (1941-1977)", novamente faz referência ao SPI e à sua continuação institucional, denominada Fundação Nacional do Índio (Funai). Nesse caso, o trabalho interessa-se pela configuração de relações interétnicas no Alto Uruguai comandadas pelos órgãos indigenistas federal e do estado do Rio Grande do Sul, visando a criação de uma frente de expansão do capital agrícola que subsumiu a força de trabalho de boa parte das populações kaingang (mais especificamente na região de Votouro). Desde o começo da década de 1940 e até o final da década de 1970, essas frentes de expansão configuraram, junto a diversos processos de territorialização, o chamado sistema de panelão como forma de controle e exploração dos Kaingang. Baseando-se tanto em fontes secundárias quanto na memória histórica dos Kaingang da região, reunida em diversos trabalhos etnográficos, os autores reconstroem a história desse sistema, explorando a relação de subordinação e conflito com as dinâmicas mais amplas do capitalismo colonial/moderno.

Relações interétnicas e dinâmicas de exploração da força de trabalho indígena no capitalismo periférico são também o foco do artigo "As práticas no extrativismo vegetal no rio Negro: políticas exíguas, imobilização da força de trabalho de povos indígenas e seu enfrentamento", da antropóloga Elieyd Sousa de Menezes. Nesse caso, o regime de engajamento laboral é conhecido como "sistema de aviamento", o qual subsume e coage os trabalhadores através de dívidas pelo adiantamento de mercadorias e dinheiro. $\mathrm{O}$ texto, resultado de mais de dez anos de pesquisa etnográfica junto aos "piaçabeiros" de Barcelos (AM), demonstra como o dito sistema, de longo alcance histórico na região, aproveita-se de "técnicas tradicionais de extrativismo vegetal", articulando-se em uma complexa rede de relações socioeconômicas que arregimenta tanto os povos indígenas da região quanto os "patrões" (comerciantes) e atores estatais. 
O artigo seguinte, de autoria de Camilo Mongua Calderón e Esther Jean Langdon, intitulado "La etno-etnohistória de los procesos de ocupación y afirmación territorial de los Tucano occidentales del río Putumayo: narrativas siona y fuentes documentales del período extractivista 1860-1930", representa um importante aporte à antropologia histórica dos grupos tucano ocidentais, especificamente os residentes da região do rio Putumayo na fronteira entre Colômbia e Equador. Comparando as narrativas da memória histórica próprias aos Siona com os estudos de corte historiográfico sobre a região, que focam nas atividades extrativas e na presença e ações das missões capuchinhas, Mongua Calderón e Langdon demonstram que essas atividades não ocupam um lugar privilegiado nas narrativas indígenas. Na verdade, nelas aparecem outros personagens e acontecimentos com maior preponderância, mobilizando uma organização de temporalidade que, embora se cruze com a cronologia da histórica oficial, está tecida a partir de modalidades "multidimensionais" entre humanos e não humanos, resultando em outras formas de organização de tempo e do espaço. Nesse sentido, a história oral siona está profundamente articulada com a memória histórica do grupo, destacando-se nela, diacronicamente, tanto os dramas sociais quanto as dinâmicas territoriais.

Território, territoralidade e processos de territorialização serão chaves analíticas também centrais na análise do artigo "A concepção Kulina de território: história e política" escrito pela antropóloga Genoveva Amorim. No seu trabalho junto aos Kulina da região do baixo rio Juruá, Amorim apresenta um complexo tecido composto por processos de territorialização e por dinâmicas comunitárias de ocupação e apropriação do espaço, assim como de fluxos migratórios, que configuraram a vida dos Kulina e suas emaranhadas relações interétnicas. Para além de apenas mapear essa paisagem geral, o artigo adentra-se com profundidade nas noções êmicas de paisagem e nos marcadores territoriais dos Kulina, tendo como horizonte a noção de "local bom". Desde esse ponto, são analisadas as narrativas orais e a sua ativação na memória histórica dos Kulina como parte de um tecido histórico-processual em que essas narrativas se apresentam sob a condição de políticas contemporâneas de (re)construir e (re)interpretar o passado.

As modalidades de construção do passado e, mais especificamente, a compreensão indígena do tempo constituem o objeto analítico do artigo de Guilherme Bianchi “'Não mais yanaconas modernos': tempo e legitimação histórica em um experimento historiográfico Misak (Cauca - Colômbia)”. 
Centrando-se na produção intelectual recente desenvolvida pelos Misak do Departamento do Cauca e seus projetos sociais, políticos e educativos, Bianchi se aprofunda na concepção misak sobre o tempo. À diferença do tempo cronológico linear, ele explicita uma percepção e compreensão pragmática do tempo, que tem na figura do "caracol" um potente modelo de explicação e interpretação histórica responsável por demonstrar a "fragilidade" de perspectivas antitéticas que organizam a temporalidade de forma binária. Nesse sentido, a compreensão pragmática da experiência temporal por parte dos Misak coloca em jogo a luta política pelo reconhecimento e pela legitimação histórica diante da sociedade nacional - incluindo o conhecimento antropológico -, processo que o autor caracteriza como "litígio cosmológico".

No seguinte artigo, "Reflexões sobre gênero e etnicidade nos cenários e repertórios de participação política no Vaupés colombiano”, a antropóloga María Rossi Idárraga faz uma interessante reconstrução histórica das principais dinâmicas do movimento indígena no Departamento de Vaupés, no qual a população indígena compõe mais de $60 \%$ da população total dessa unidade político-territorial. A partir da perspectiva dos estudos antropológicos sobre gênero, etnicidade e poder, o trabalho analisa um marco temporal que começa em 1970 - com a efetivação da primeira organização regional indígena - e termina em 2010, evidenciando importantes mudanças com relação à participação e ao protagonismo das mulheres dentro do movimento indígena. A autora se interessa nesse interstício temporal em destacar a articulação entre as alterações administrativas estatais nos territórios do Vaupés e as transformações nas relações de gênero dentro desse processo. No percurso histórico demarcado no artigo, o território é revalorizado etnicamente enquanto fundamento dos direitos e práticas políticas, ao mesmo tempo que vão se configurando novas espacialidades, significados e repertórios que fornecem dinâmicas inéditas à participação das mulheres indígenas.

Também desde uma antropologia histórica com foco nos processos políticos, mais especificamente nos processos de descolonização, o trabalho de Fabio Mura, Alexandra Barbosa da Silva e Rubem Ferreira Thomaz de Almeida ( $\dagger$ ) "Relações de poder e processo de descolonização na Reserva Indígena de Dourados, Mato Grosso do Sul: uma análise", propõe uma leitura das relações de poder na Reserva Indígena de Dourados (MS). Nele se mostra, através de revisão historiográfica, mas sobretudo da longa trajetória de pesquisa etnográfica 
dos autores na região, como se conectam vários níveis de organização política, de escalas espaciais e de processos históricos. $\mathrm{O}$ artigo traz uma importante contribuição metodológica ao explorar esses diversos níveis de análise, bem como ao focalizar a trajetória dos distintos grupos domésticos, seus processos de dominalização e suas articulações históricas em comunidades políticas maiores. Esses movimentos estão inseridos em processos e dinâmicas mais amplas, que vinculam as comunidades políticas indígenas a grupos sociais não indígenas e agentes e órgãos estatais, em uma complexa e cambiante estrutura de relações interétnicas que demonstra a heterogeneidade das estratégias dos grupos domésticos kaiowa e ñandéva.

Não por acaso, este número temático de Horizontes Antropológicos é encerrado com o trabalho do antropólogo wapichana Eriki Aleixo Wapichana denominado "Sociogênese da mobilização étnica ocorrida na comunidade Serra do Truarú (Terra Indígena Serra da Moça, etnorregião Murupú, Boa Vista-RR)”. Partindo de fontes históricas e do trabalho etnográfico e político do próprio autor, o artigo aplica a noção de etnogênese, proposta por Norbert Elias, para descrever e analisar o importante processo de "mobilização etnopolítica" acontecido na comunidade Serra do Truarú dentro da Terra Indígena (TI) Serra da Moça (RR). Caraterizada pelo autor como um território pluriétnico de maioria wapichana, mas também habitado por indígenas macuxi e não indígenas, a luta pelo território e pelos direitos das populações indígenas tem sido um dos elementos centrais da configuração dessa região. Dessa forma, o importante trabalho de Aleixo Wapichana historiciza os antecedentes e analisa as configurações das mobilizações étnicas, destacando o papel das lideranças locais na luta pelo território.

Na seção Espaço Aberto, fora do eixo temático do número, o artigo de Ronaldo Almeida sobre a trajetória e ascensão política do setor evangélico alinhado ao conservadorismo de direita e suas estratégias nos últimos anos tem uma pertinência sociopolítica fundamental no que concerne às populações indígenas do Brasil e à sociedade brasileira em geral dentro da atual e preocupante conjuntura.

Também no Espaço Aberto e fechando esta edição da revista, apresentamos três trabalhos que tratam das implicações da pandemia de Sars-CoV-2. Paula Escribano, Agata Hummel e Claudio Milano analisam o impacto da decretação de emergência sanitária pelo Estado espanhol, em decorrência da Covid 19, no circuito do mercado agroalimentar. A partir de fontes etnográficas advindas das regiões metropolitanas de Madri e Barcelona, envolvendo tanto produtores 
quanto consumidores agroecológicos, os autores destacam a importância das trocas informais no suprimento de alimentos durante o período de confinamento, bem como as estratégias que tornaram possível a manutenção desse mercado apesar das restrições impostas pelo Estado. Handerson Joseph e Federico Neiburg abordam as implicações econômicas e sociais, bem como o sofrimento imposto pela imobilidade causada pela pandemia no Haiti. $\mathrm{O}$ artigo traça um panorama dos efeitos produzidos pelo novo coronavírus e expõe os retornos voluntários e involuntários (como no caso das deportações dos Estados Unidos), a diminuição sensível do envio de remessas em dinheiro, as restrições ao comércio e o vaivém entre o campo e a cidade. Heitor Frúgoli Jr. analisa, a partir do diário de Susana Bragatto publicado na Folha de S. Paulo entre março e junho de 2020 , as especificidades das dinâmicas de isolamento social e desconfinamento no contexto europeu, com atenção às novas configurações dos usos dos espaços domésticos e sobretudo às formas de interação face a face nos espaços públicos na cidade de Barcelona. Ele tece contrapontos com a experiência brasileira, mais especificamente em São Paulo, dando atenção aos impactos da pandemia na vida urbana.

As antropologias históricas deste número de Horizontes Antropológicos são uma mostra da continuidade das lutas dos povos indígenas, aspecto esse que está simbolizado na própria escolha da imagem de capa: uma liderança kamaiurá de pé em frente ao "Palácio do Congresso Nacional" sob uma forte presença policial durante o Acampamento Terra Livre em abril de 2017.

Finalmente, é necessário dedicar algumas linhas a título de reconhecimento. Primeiramente para todas/os as/os autoras/es que submeteram seus manuscritos à publicação neste número de Horizontes Antropológicos; foram mais de quarenta textos que, por conta do formato e das possibilidades financeiras da revista, precisaram ser necessariamente reduzidos a onze. Em segundo lugar, para todas/os as/os pareceristas que, com comprometimento, doaram horas de trabalho e esforço na avaliação cuidadosa dos artigos. Ademais, faz-se necessário também agradecer as/os editores de Horizontes Antropológicos Arlei Sander Damo, Ari Oro, Fernanda Rifiotis e Ruben Oliven, pela oportunidade dada à temática e pelo grande empenho e cuidado com a qualidade do número. E, por último, mas não menos importante, é preciso destacar o excelente e comprometido trabalho técnico profissional de Cristiane Miglioranza e Cleber Rocha das Neves, sem o qual seria impossível concluir esta publicação. 


\section{Referências}

ABU-LUGHOD, L. Writing against culture. In: FOX, R. (ed.). Recapturing anthropology: working in the present. Santa Fe: School of American Research, 1991. p. 137-162.

AGIER, M. Gérer les indésirables: des camps de réfugiés au gouvernement humanitaire. Paris: Flammarion, 2010.

AMSELLE, J.-L. (ed.). Le sauvage à la mode. Paris: Le Sycomore, 1979.

AMSELLE, J.-L.; M'BOKOLO, E. (org.). No centro da etnia: etnias, tribalismo e Estado na África. Petrópolis: Vozes, 2017.

ARGUEDAS, J. M. Formación de una cultura nacional indoamericana. México: Siglo XXI, 1975.

ASAD, T. (ed.). Anthropology and the colonial encounter. Reading: Ithaca Press, 1973.

AUGÉ, M. Théorie des pouvoirs et idéologie du pouvoir en basse Côte d’Ivoire. Paris: Hermann, 1975.

BALANDIER, G. Sociologie actuelle de l'Afrique noire: dynamique der changements sociaux un Afrique Centrale. Paris: Presses Universitaires de France, 1955.

BARNES, J. A. Politics in a changing society. Manchester: Manchester University Press, 1954.

BAZIN, J. Des clous dans la Joconde: l'anthropologie autrement. Toulouse: Éditions Anacharsis, 2014.

BENSA, A. Chroniques kanak: l'ethnologie en marche. Paris: Survival International, 1995.

BENSA, A. Después de Lévi-Strauss: por una antropología a escala humana. México: Fondo de Cultura Económica, 2015.

BENSA, A. El fin del exotismo: ensayos de antropología crítica. Zamora: El Colegio de Michoacán, 2016.

BLOCH, M. Los reyes taumaturgos. México: Fondo de Cultura Económica, 1996.

BLOCH, M. (ed.). Análisis marxistas y antropología social. Barcelona: Anagrama, 1975.

BONFIL BATALLA, G. El concepto de indio en América: una categoría de la situación colonial. In: BONFIL BATALLA, G. Identidad y pluralismo cultural en América Latina. San Juan: Universidad de Puerto Rico, 1992. p. 25-48. 
CARDOSO DE OLIVEIRA, R. A sociologia do Brasil indígena. Rio de Janeiro: Tempo Brasileiro, 1978.

CASIMIR, J. La cultura oprimida. México: Nueva Imagen, 1980.

CLIFFORD, J.; MARCUS, G. (ed.). Retóricas de la antropología. Barcelona: Júcar, 1991.

COHN, B. S. An anthropologist among the historians and other essays. London: Oxford University Press, 1992.

COMAROFF, J.; COMAROFF, J. Ethnography and the historical imagination. Boulder: Westview Press, 1992.

COPANS, J. (org.). Antropologia: ciência das sociedades primitivas?. Lisboa: Edições $70,1988$.

CORONIL, F. Más allá del occidentalismo: hacia categorías geo-históricas no imperiales. Casa de las Américas, n. 214, p. 21-49, 1999.

CORONIL, F. Pieces for anthrohistory: a puzzle to be assembled together. In: COHEN, D. et al. (ed.). Anthrohistory: unsettling knowledge, questioning discipline. Ann Arbor: University of Michigan Press, 2011. p. 301-316.

DARNTON, R. La gran matanza de gatos y otros episodios en la historia de la cultura francesa. México: Fondo de Cultura Económica, 1995.

DÍAZ-POLANCO, H. Elogio de la diversidad. La Habana: Casa de las Américas, 2008.

DUMONT, L. Homo hierarchicus: essai sur le système des castes. Paris: Gallimard, 1966.

DUSSEL, E. El encubrimiento del otro: hacia el origen del mito de la modernidad. Quito: Abya-Yala, 1994.

ELIAS, N. La sociedade de los indivíduos. Barcelona: Península, 1987.

EVANS-PRITCHARD, E. E. Essays in social anthropology. London: Faber \& Faber, 1962.

FABIAN, J. O tempo e o outro: como a antropologia estabelece seu objeto. Petrópolis: Vozes, 2013.

FAHIM, H. (ed.). Indigenous anthropology in non-western countries. Durham: Carolina Academic Press, 1982.

FOUCAULT, M. História da sexualidade I: a vontade de saber. São Paulo: Graal, 1985.

GALVÃO, E. Encontro de sociedades: índios e brancos no Brasil. São Paulo: Paz e Terra, 1979. 
GEERTZ, C. El salvaje cerebral: sobre la obra de Claude Lévi-Strauss. In: GEERTZ, C. La interpretación de las culturas. Barcelona: Gedisa, 1987. p. 287-298.

GINZBURG, C. O queijo e os vermes. São Paulo: Companhia das Letras, 1987.

GLEDHILL, J. The peasantry in history: some notes on Latin American research. Critique of Anthropology, v. 5, n. 1, p. 33-56, 1985.

GLEDHILL, J. El podery sus disfraces: perspectivas antropológicas de la política. Barcelona: Bellaterra, 2000.

GLUCKMAN, M. Malinowski's functional analysis of social change. In: GLUCKMAN, M. Order and rebellion in Tribal Africa. London: Routledge, 1963. p. 207-234.

GOODY, J. The development of the family and marriage in Europe. Cambridge: Cambridge University Press, 1983.

GOODY, J. A domesticação da mente selvagem. Petrópolis: Vozes, 2012.

GRANET, M. La pensée chinoise. Paris: Albin Michel, 1968.

GRIAULE, M. Masques Dogons. Paris: Institut d’Ethnologie, 1938.

HALBWACHS, M. La memoire collective. Paris: Les Presses Universitaires de France, 1950.

HARRIS, M. El desarrollo de la teoría antropológica. México: Siglo XXI, 1979.

HARRIS, M. Rebellion on the Amazon: the Cabanagem, race, and popular culture in the north of Brazil, 1798-1840. Cambridge: Cambridge University Press, 2010.

INGOLD, T. The appropriation of nature: essays on human ecology and social relations. Iowa City: University of Iowa Press, 1987.

KEITH, T. Religion and the decline of magic. London: Weidenfeld \& Nicholson, 1971.

LANDER, E. Ciencias sociales: saberes coloniales y eurocéntricos. In: LANDER, E. (ed.). La colonialidad del saber: eurocentrismo y ciencias sociales. Buenos Aires: Consjeo Latinaomericano de Ciencias Sociales, 2000. p. 11-40.

LEACH, E. R. Replanteamiento de la antropología. Barcelona: Seix Barral, 1972.

LEENHARDT, M. Do Kamo: la personne et le mythe dans le monde mélanésien. Paris: Gallimard, 1947.

LÉVI-STRAUSS, C. Antropologia estrutural. Rio de Janeiro: Zahar, 1967. 
MALINOWSKI, B. Argonautas do Pacífico ocidental. São Paulo: Abril, 1978.

MARX, K. Teses sobre Feuerbach. In: MARX, K.; ENGELS, F. A ideologia alemã. São Paulo: Boitempo, 2007. p. 533-535.

MAUSS, M. Sociologia e antropologia. São Paulo: Cosac Naify, 2003.

MENÉNDEZ, E. Racismo, colonialismo y violência científica. Buenos Aires: Centro Editor de América Latina, 1971.

MINTZ, S. Dulzura y poder. México: Fondo de Cultura Económica, 1996.

MURRAY, M. El culto de la brujería en la Europa occidental. Barcelona: Labor, 1971.

NASH, J. Crafts in the world market: the impact of global exchange on Middle American artisans. Albany: State University of New York Press, 1993.

NASH, J. Comemos a las minas y las minas nos comen a nosotros. Buenos Aires: Antropofagia, 2008.

ORTIZ, F. Contrapunteo cubano del tabaco y el azúcar. Caracas: Biblioteca Ayacucho, 1978.

PACHECO DE OLIVEIRA, J. Ensaios em antropologia histórica. Rio de Janeiro: Universidade Federal do Rio de Janeiro, 1999.

PACHECO DE OLIVEIRA, J. Etnografia enquanto compartilhamento e comunicação; desafios atuais às representações coloniais. In: FELDMAN-BIANCO, B. (org.). Desafios da antropologia brasileira. Brasília: Associação Brasileira de Antropologia, 2013. p. 47-74.

PACHECO DE OLIVEIRA, J.; SANTOS, R. C. M. Introdução. In: PACHECO DE OLIVEIRA, J.; SANTOS, R. C. M. (org.). De acervos coloniais aos museus indígenas: formas de protagonismo e de construção da ilusão museal. João Pessoa: Universidade Federal da Paraíba, 2019. p. 7-25.

PALERM, A. Antropología y marxismo. México: Nueva Imagen, 1980.

PETERSON, M. A. Anthropology and mass communication: media and myth in the new millennium. Oxford: Berghahn Books, 2003.

PRATT, M. L. Ojos imperiales: literatura de viajes y transculturación. Bernal: Universidad Nacional de Quilmes, 1997.

QUIJANO, A. El movimiento indígena y las cuestiones pendientes en América Latina. Argumentos, n. 50, p. 51-77, 2006. 
QUINTERO, P. Antropología del desarrollo: perspectivas latinoamericanas. Buenos Aires: Kula, 2015.

QUINTERO, P. Colonialidad del poder, comunidades indígenas y economías alternativas. In: MARAÑÓN, B. (ed.). Solidaridad económica y potencialidades de transformación en América Latina. Buenos Aires: Consejo Latinoamericano de Ciencias Sociales, 2012. p. 103-124.

RAPPAPORT, J. Cumbe reborn: an Andean ethnography of history. Chicago: University of Chicago Press, 1994.

RIBEIRO, D. Os índios e a civilização. Rio de Janeiro: Civilização Brasileira, 1970.

RIBEIRO, G. L.; ESCOBAR, A. (org.). Antropologias mundiais: transformações da disciplina em sistemas de poder. Brasília: Universidade de Brasília, 2012.

RODRÍGUEZ, O. Etnias, imperios y antropología. Caracas: Universidad Central de Venezuela, 1991.

ROSEBERRY, W. Anthropologies and histories: essays in culture, history, and political economy. London: Rutgers University Press, 1989.

SAHLINS, M. Ilhas de história. Rio de Janeiro: Zahar, 1990.

SAID, E. Cultura e imperialismo. Barcelona: Anagrama, 1996.

SAID, E. A representação do colonizado: os interlocutores da antropologia. In: SAID, E. Reflexões sobre o exílio e outros ensaios. São Paulo: Companhia das Letras, 2003. p. 114-136.

SIDER, G. Culture and class in anthropology and history: a Newfoundland illustration. Cambridge: Cambridge University Press, 1988.

STAVENHAGEN, R. Las clases sociales en las sociedades agrarias. México: Siglo XXI, 1969.

STOCKING, G. W. Race, culture, and evolution: essays in the history of anthropology. Chicago: University of Chicago Press, 1982.

STOLER, A. L. Along the archival grain: epistemic anxieties and colonial common sense. Princeton: Princeton University Press, 2010.

TAUSSIG, M. Xamanismo, colonialismo e o homem selvagem. São Paulo: Paz e Terra, 1993.

THOMPSON, E. P. Costumbres en común. Barcelona: Crítica, 1995. 
TROUILLOT, M. R. Anthropology and the savage slot: the poetics and politics of the otherness. In: FOX, R. (ed.). Recapturing anthropology: working in the present. Santa Fe: School of American Research, 1991. p. 17-44.

TUHIWAI SMITH, L. Decolonizing methodologies: research and indigenous people. London: University of Otago: Zed Books, 1999.

TURNER, V. W. Schism and continuity in na African Society. Manchester: Manchester University Press, 1957.

VARGAS, I. La historia como futuro. Caracas: Universidad Central de Venezuela, 1980.

VIVEIROS DE CASTRO, E. Images of nature and society in Amazonian Ethnology. Annual Review of Anthropology, n. 25, p. 179-200, 1996.

WALLERSTEIN, I. The modern world-system I: capitalist agriculture and the origins of the European World-Economy in the sixteenth century. New York: Academic Press, 1974.

WARMAN, A. De eso que llaman antropología mexicana. México: Nuestro Tiempo, 1970.

WOLF, E. Europa e os povos sem história. São Paulo: Edusp, 2009. 